Special issue of the 3rd International Conference on Computational and Experimental Science and Engineering (ICCESEN 2016)

\title{
Comparison of Excitation Functions of Longer and Shorter Lived Radionuclides
}

\author{
S.S. NOORI ${ }^{a *}$, İ. AKKURT ${ }^{a}$ AND N.K. DEmiR ${ }^{b}$ \\ ${ }^{a}$ Süleyman Demirel University, Sciences and Arts Faculty, Isparta, Turkey \\ ${ }^{b}$ Amasya University, Sabuncuoğlu Şerefeddin Vocational School of Health Services, Amasya, Turkey \\ Nuclear reactions, which are very important from the point of view of human health, may occur during the \\ production of the radiation sources, used in radiotherapy. The nuclear reaction data are needed in the radioisotope \\ production procedure. The total cross section is also important in accelerator technology, in view of radiation \\ protection and safety. In general, the significance of the cross section data for nuclear reactions in radionuclide \\ production programs is firmly established. Gamma irradiation tracers can offer a large amount of information \\ about the anatomy of different organs in the human body. The main purpose of this work was to compare the \\ cross section of longer-shorter lived radionuclides. Theoretical excitation functions have been calculated with \\ TALYS 1.6 nuclear reaction simulation code. The calculated results have been discussed and compared with the \\ experimental data.
}

DOI: 10.12693/APhysPolA.132.1186

PACS/topics: Radionuclides, Gamma Irradiation, TALYS 1.6 nuclear reaction simulation code

\section{Introduction}

Nuclear techniques play an important role in many facets of our daily life and are an integral part of our socioeconomic development, such as in food security and and peservation, medical diagnostics and treatment, agriculture, insect control, etc.

Production of safe and clean energy is an important problem of today's world. Reactors and cyclotrons are used for radionuclide production. Production of medical isotopes is an important and permanently evolving issue $[1,2]$. The cross-section data for nuclear reactor production are generally well-known and can be satisfactorily reproduced by nuclear model calculations. In particular, if the experimental measurements are unobtainable or are improbable to be produced because of the experimental difficulties, then theoretical models of nuclear reactions are needed to obtain the prediction of the reaction cross-sections.

\section{Materials and methods}

Calculations, based on models of nuclear reactions, play an important part in the development of reaction cross sections. Cross section concept in the laboratory is based upon a consideration of the physical case, encountered in determining reaction probability.

An incident collimated beam of particles collides with the target nuclei in a suitable specimen of material and through the processes of scattering, interacts with it by absorption and/or reaction, here by losing energy or intensity, or both, by an amount which can be determined by measurements of the emerging beam [3].

*corresponding author; e-mail: suzan_nuclear@yahoo.com
In this study, excitation functions of the gamma reactions for short lived radionuclides like ${ }^{12} \mathrm{C}(\mathrm{g}, \mathrm{n}){ }^{11} \mathrm{C},{ }^{14} \mathrm{~N}(\mathrm{~g}$, $\mathrm{n}){ }^{13} \mathrm{~N},{ }^{16} \mathrm{O}(\mathrm{g}, \mathrm{n}){ }^{15} \mathrm{O}$, and for long lived radionuclides ${ }^{19} \mathrm{~F}$ $(\mathrm{g}, \mathrm{n}){ }^{18} \mathrm{~F},{ }^{65} \mathrm{Cu}(\mathrm{g}, \mathrm{n}){ }^{64} \mathrm{Cu}$, have been calculated using nuclear reaction simulation code TALYS 1.6. TALYS is a Monte Carlo code. It is a nuclear reaction simulation computer code system for the analysis and prediction of nuclear reactions [4].

The most favorable choice of the radionuclide, to maximize the therapeutic index, depends on a number of factors. First, the range of the particles, emitted from the radionuclide, should depend on the type of tumor being treated. A second important consideration is the choice of the half-life of the radionuclide. If the half-life is too short, then the radiolabeled tumor targeting agent may have insufficient time to reach its target, resulting in a minimal therapeutic index. Increasing the half-life will increase the therapeutic index, but render the patient radioactive for a longer period of time, resulting in prolonged confinement, greater expense and radiation risks to staff and family.

Pure $\beta+$ emitting radionuclides such as ${ }^{11} \mathrm{C},{ }^{13} \mathrm{~N},{ }^{15} \mathrm{O}$, ${ }^{18} \mathrm{~F}$ and ${ }^{64} \mathrm{Cu}$ isotopes have advantages, because they minimize the exposure of the personnel, assisting patients. The half-life of the radionuclide should ideally match the biological uptake and retention kinetics of the tumortargeting carrier. For large protein carriers, such as antibodies, to optimize the therapeutic index, radionuclides with half-lives of several days are required. For smaller molecular targeting agents, such as peptides, to minimize radioactive waste, the short lived radionuclides may be better suited [5].

\section{Results and discussion}

The results of calculation of the excitation function for gamma reactions of the short lived radionuclides, carried 
out using TALYS 1.6, are plotted in Figs. 1-3, together with the experimental data from the EXFOR 2016 library.

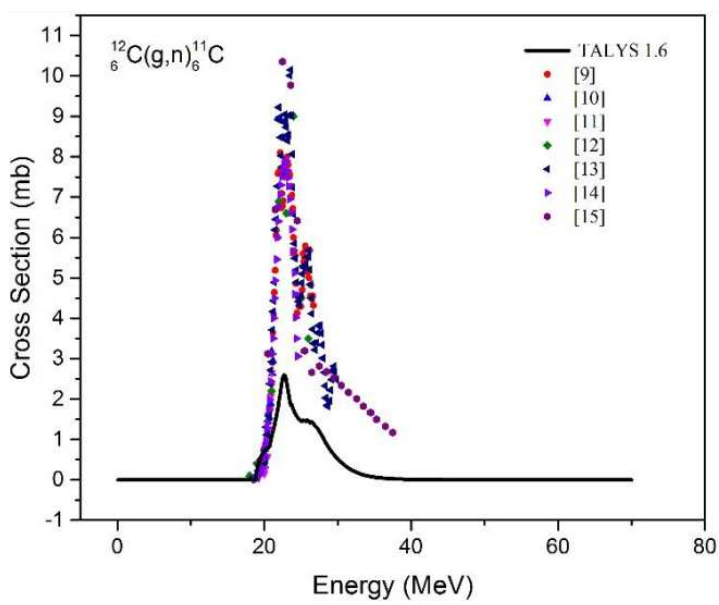

Fig. 1. Excitation functions for the gamma reaction ${ }^{12} \mathrm{C}(\mathrm{g}, \mathrm{n}){ }^{11} \mathrm{C}$.

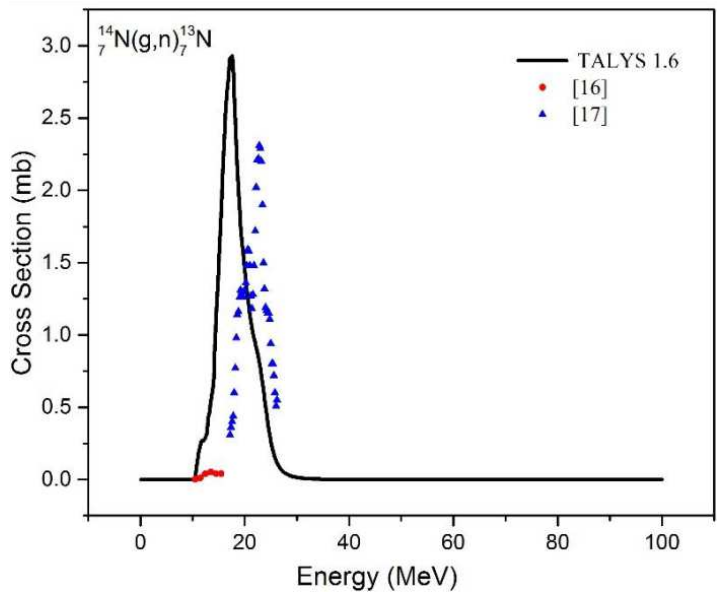

Fig. 2. Excitation functions for the gamma reaction ${ }^{14} \mathrm{~N}(\mathrm{~g}, \mathrm{n})^{13} \mathrm{~N}$.

The ${ }^{11} \mathrm{C}$ radioisotope, which has a half-life of 20.334 minutes, is formed by the reaction ${ }^{12} \mathrm{C}(\mathrm{g}, \mathrm{n}){ }^{11} \mathrm{C}$. The reaction cross-sections are shown in Fig. $1 .{ }^{11} \mathrm{C}$-acetate PET was originally employed in cardiology to study myocardial perfusion. It has also been used to study the myocardial oxygen metabolism, as well as in oncology. The first studies of $11 \mathrm{C}$-acetate were focused on its use in prostate cancer. Subsequently, ${ }^{11} \mathrm{C}$-acetate was studied in urological malignancies, as well as in bladder cancer and renal cell carcinoma [6].

${ }^{13} \mathrm{~N}$ is a radioisotope of nitrogen. It has a half-life of $9.9670 \mathrm{~min}$ and is used in positron emission tomography $(\mathrm{PET})$. It is produced by the reaction ${ }^{14} \mathrm{~N}(\mathrm{~g}, \mathrm{n}){ }^{13} \mathrm{~N}$. Because of short half-life, it must be made at the PET site by using a cyclotron. ${ }^{13} \mathrm{~N}$ is used to tag ammonia molecules for PET myocardial perfusion imaging [7]. The measured cross sections with experimental data are given in Fig. 2.

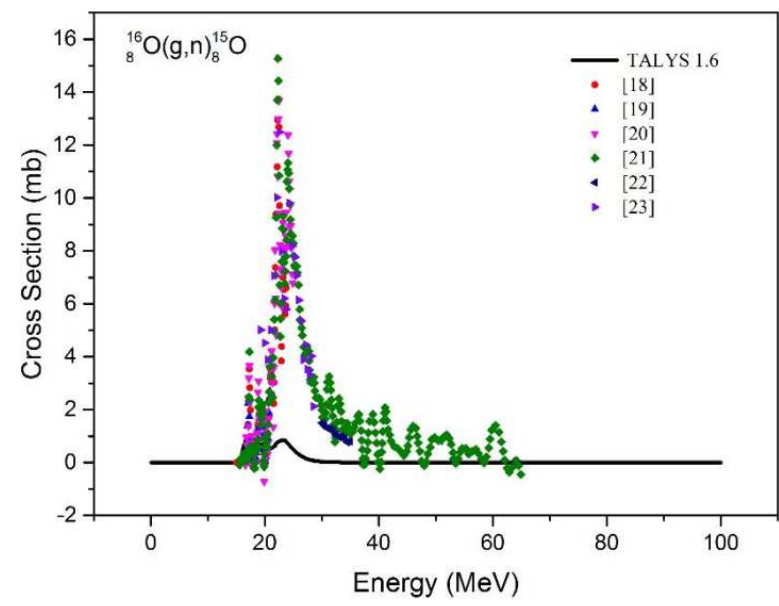

Fig. 3. Excitation functions for the gamma reaction ${ }^{16} \mathrm{O}(\mathrm{g}, \mathrm{n}){ }^{15} \mathrm{O}$.

Another important isotope in (PET) technique is ${ }^{15} \mathrm{O}$. It has a half-life of approximately two minutes (122.24 seconds) [8]. It is produced by the reaction of ${ }^{16} \mathrm{O}(\mathrm{g}, \mathrm{n})^{15} \mathrm{O}$. ${ }^{15} \mathrm{O}$ is used in the study of blood flow in the brain tomographic imaging. In the diagnostic imaging this isotope is incorporated into molecules by inhaling or injection, then it accumulates in the diagnosed or studied organ or region of the human body. The cross section of ${ }^{15} \mathrm{O}$ is shown in Fig. 3.

The results for long lived radionuclides are shown in Figs. 4 and 5 . The ${ }^{18} \mathrm{~F}$ has a physical half-life of 110 minutes, which is considerably longer than the physical half-life of its parent molecule. It is produced by the reaction of ${ }^{19} \mathrm{~F}(\mathrm{~g}, \mathrm{n}){ }^{18} \mathrm{~F}$ and is used as the trace in the study of the brain and in the diagnostic imaging. The measured cross sections, with the experimental data, are given in Fig. 4.

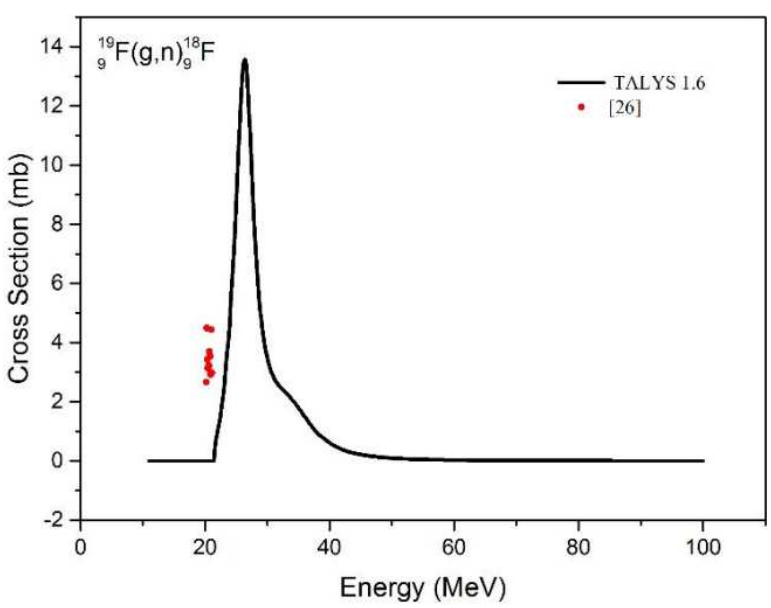

Fig. 4. Excitation functions for the gamma reaction of ${ }^{19} \mathrm{~F}(\mathrm{~g}, \mathrm{n}){ }^{18} \mathrm{~F}$.

The half-live of ${ }^{64} \mathrm{Cu}$ is 12.70 hours [9]. It is produced by the reaction of ${ }^{65} \mathrm{Cu}(\mathrm{g}, \mathrm{n}){ }^{64} \mathrm{Cu}$. The longer half-life allows to produce ${ }^{64} \mathrm{Cu}$ at national or regional cyclotrons, 
and then, with the loss of approximately one half-life, to distribute it to local nuclear medicine departments [10]. ${ }^{64} \mathrm{Cu}$ is used in PET in diagnosis of the blood supply to the kidney, in diagnostic imaging, in studies of radiation doses measuring and in colorectal cancer treatment. The cross section of ${ }^{65} \mathrm{Cu}(\mathrm{g}, \mathrm{n}){ }^{64} \mathrm{Cu}$ is presented in Fig. 5 .

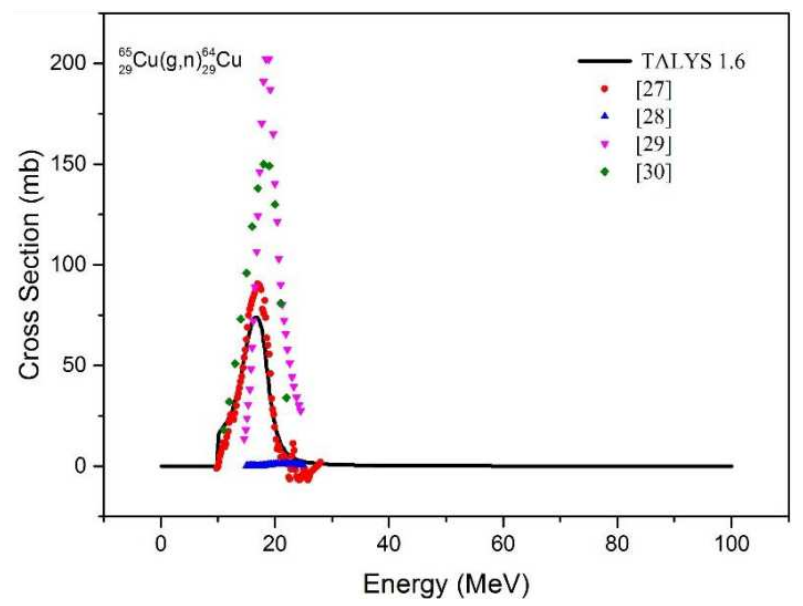

Fig. 5. Excitation functions for the gamma reaction ${ }^{65} \mathrm{Cu}(\mathrm{g}, \mathrm{n}){ }^{64} \mathrm{Cu}$

It can be seen from this work, that the experimental cross-sections (EXFOR) are in general in agreement with the results of theoretical calculations of TALYS 1.6. However, the peak value of the calculated curves in some nuclei is smaller than the experimental value. In ${ }^{19} \mathrm{~F}(\mathrm{~g}, \mathrm{n}){ }^{18} \mathrm{~F}$ reaction we cannot make the comparison, because of the lack of adequate experimental data. As we have shown in Fig. 4, there is only one preceding study.

All of the above nuclei decay with the emission of positive beta. $\beta+$ are employed in positron emission tomography, which is used in the diagnosis and early detection of tumors and cancers of different organs of the human body. This technology can be used as well to trace the biologic pathway of any compound in living humans.

\section{Conclusions}

Radioactive nuclei, are frequently used in the detection and diagnosis by PET. ${ }^{18} \mathrm{~F}$ has a long half-life of about 110 minutes and it is frequently used in such investigations. Due to long half-life it can be transported for long distances (about 200 kilometers) to the hospital where it is required. As for radioactive nuclei with short half-life, these can be used only in the event when the hospital is close to the scientific center in which the radioactive elements are produced in a cyclotron. To achieve the speed of the transfer of the radioactive nuclei, the ${ }^{18} \mathrm{~F}$ is used in about $90 \%$ of cases.

\section{References}

[1] S.M. Qaim, Radiat. Phys. Chem. 71, 917 (2004).

[2] B.L. Zhuikov, Appl. Radiat. Isotop. 84, 48 (2004).

[3] S.A.A.M. Issa, Ph.D. Thesis, Experimental Nuclear Physics, Al-Azhar University Faculty of Science Assiut, Egypt 2009.

[4] A.J. Koning, D. Rochman, Nucl. Data Sheets 113, 2841 (2012)

[5] D.L. Bailey J.L. Humm, A. Todd-Pokropek, A. van Aswegen, Nuclear Medicine Physics: a Handbook for Teachers and Students, IAEA, STI/PUB/1617, 2014

[6] I. Grassi, C.N.V. Allegri, J.J. Morigi, G.C. Montini, P. Castellucci, S. Fanti, Am. J. Nucl. Med. Mol. Imaging 2, 33 (2012).

[7] A.C. Phillips, The Physics of Stars, John Wiley \& Sons, 1994.

[8] IAEA (International Atomic Energy Agency), Handbook on Nuclear Medicine Resources Manual, Vienna, STI/PUB/1198, 2006.

[9] A. Gholamrezanezhad, 12 Chapters on Nuclear Medicine, InTech, Croatia 2011.

[10] C.J. Anderson, R. Ferdani, Cancer Biotherapy Radiopharmaceut. 24, 379 (2009). 